\title{
Does Podocyte-Associated Protein Has A Role in Early Detection of Diabetic Nephropathy in Type 2 Diabetes Mellitus?
}

\author{
MOHAMED A.R. EL-ZAMAR, M.Sc.; OLA A.F. EL-SHORA, M.D.; GHADA M. AL-GHAZALY, M.D. and \\ MOHAMED H. ABO FREIKHA, M.D.
}

The Department of Internal Medicine, Faculty of Medicine, Tanta University, Egypt

\begin{abstract}
Background: Diabetic nephropathy or Diabetic Kidney Disease (DKD) became a major public health concern worldwide because it is a major cause of end stage renal disease. Early intervention can significantly improve the prognosis. Urinary podocyte-associated protein is elevated in patients with DKD, so it is a promising way in early detection of DKD.

Aim of Study: To investigate the role of podocyte associated protein in early detection of diabetic nephropathy in patients with type 2 diabetes mellitus.

Patients and Methods: A cross sectional study was done on 90 patients divided equally into three groups (normoalbumiuria, microalbumiuria and macroalbumiuria) plus 10 healthy individuals as controls.

Results: All diabetic patients had a higher level of urinary podocyte-associated protein than control group. Also, there was positive correlation between urinary podocyte-associated protein and the degree of albuminuria. So, it was increased with the severity of renal involvement.

Conclusion: This study demonstrated that measurement of urinary podocyte-associated protein is a potential biomarker for the early detection of DKD.
\end{abstract}

Key Words: Diabetic kidney disease - Podocyte associated protein-Type 2 diabetes mellitus.

\section{Introduction}

DIABETES mellitus is a group of metabolic diseases characterized by hyperglycemia due to deficiency of insulin secretion, insulin resistance or to a combination of both [1]. Long-term complications of DM include peripheral neuropathy, retinopathy and nephropathy leading to renal failure [2].

Correspondence to: Dr. Mohamed A.R. El-Zamar, The Department of Internal Medicine, Faculty of Medicine, Tanta University, Egypt
Diabetic Kidney Disease (DKD) is one of the most serious complications which impacts morbidity, mortality and quality of life. It occurs in approximately one-third of all people with diabetes. DKD is characterized by progressive impairment of glomerular function leading to end stage renal disease in 5 stages; stage I (hypertrophic hyperfiltration), stage II (silent stage), stage III (microalbuminuria stage), stage IV (chronic kidney failure) and stage V (terminal kidney failure) [3] .

The first clinical sign of DKD is microalbuminuria however, morphological changes may occur earlier. Although, microalbuminuria is widely used as the best marker of the onset of DKD. Serum creatinine and Blood Urea Nitrogen (BUN) which, reflect kidney function, are routinely used as markers of DKD, however, they are insensitive because functional changes in the kidney occur in late stages when the damage has become widespread [4].

Podocalyxin is an integral membrane protein coating the secondary foot processes of kidney podocytes [5]. The apical region of Podocytes is proximal to the urinary space so any pathological events occurring in this region are more easily detectable in urine than those occurring in the basal regions of Podocytes [6]. It is now known to play a role in podocytes morphogenesis and maintenance of structural integrity [7].

\section{Patients and Methods}

This study was across sectional targeting adult male and female with type 2 diabetes mellitus aged between 30-70 years during the period from June 2017 to June 2018 from internal wards and outpatients diabetic clinics of Internal Medicine Department Tanta University Hospitals. Another group 
of apparently healthy individuals were included in the study as the control group.

\section{Sample size:}

The sample size was 90 patients who were previously diagnosed as having type 2 diabetes mellitus as cases and 10 healthy individuals as control. An informed written consent was obtained from all participants in the research and an approval of Ethical Committee of Tanta University Hospitals was obtained.

They were divided into 3 main groups according to their urinary albumin excretion in addition to the control group.

1- Group I: It included 30 diabetic patients with normoalbuminuria ( $<30 \mathrm{mg} / 24 \mathrm{hours})$.

2- Group II: It included 30 diabetic patients with microalbuminuria (30-299mg/24hours).

3- Group III: It included 30 diabetic patients with macroalbuminuria (>300mg/24hours).

4- Group IV: It included 10 healthy individuals as control.

\section{Inclusion criteria:}

Patients with type 2 diabetes mellitus.

\section{Exclusion criteria:}

1- Type 1 diabetic patients.

2- Patients with known kidney disease whatever the cause.

3- Patients with uncontrolled hypertension.

4- Patients with fever.

5- Patients with Urinary Tract Infection (UTI).

6- Patients with congestive heart failure.

7- Patients with severely uncontrolled $\mathrm{DM}\left(\mathrm{HbA}_{1 \mathrm{c}}\right.$ $>9 \%$ ).

8- Menstruating and pregnant female patients.

All patients and controls were subjected to:

1- Full medical history.

2- Complete clinical examination.

3- Blood pressure measurement (systolic and diastolic) and (supine and erect).

4- Routine laboratory investigations including:

A- Complete urine analysis.

B- Fasting and 2 hours postprandial blood sugar.

C- Glycosylated hemoglobin $\left(\mathrm{HbA}_{1 \mathrm{c}}\right)$.

D- Complete blood picture.
E- Renal function tests (serum creatinine, blood urea).

F- Serum albumin.

G- C-Reactive Protein (CRP).

H- Kidney microalbuminuria.

I- Albumin/Creatinine Ratio (ACR).

5- Specific investigations, measurement of podocyte-associated protein in urine by ELISA.

\section{Results}

Systolic Blood Pressure (SBP) was statistically highly significant increased in Group III (mean $( \pm \mathrm{SD})$ was $82.833 \pm 7.621)$ in comparison to Group I (mean $( \pm$ SD) was $69.333 \pm 8.880)$ \& Group IV (mean $( \pm$ SD) was $69.500 \pm 4.972)$. Fig. (1).



Fig. (1): Comparison between studied groups regarding SBP.

Diastolic Blood Pressure (DBP) showed highly significant increase in Group II (mean $( \pm$ SD) was 78. $167 \pm 7.250 \mathrm{mmHg}$ ) when compared with Group I (mean $( \pm \mathrm{SD})$ was $69.333 \pm 8.880 \mathrm{mmHg})(p$-value $<0.05)$. There was statistically highly significant increase of DBP in Group III (mean $( \pm \mathrm{SD})$ was $82.833 \pm 7.621 \mathrm{mmHg}$ ) in comparison to Group IV (mean $( \pm \mathrm{SD})$ was $69.500 \pm 4.972 \mathrm{mmHg})$. Fig. (2).

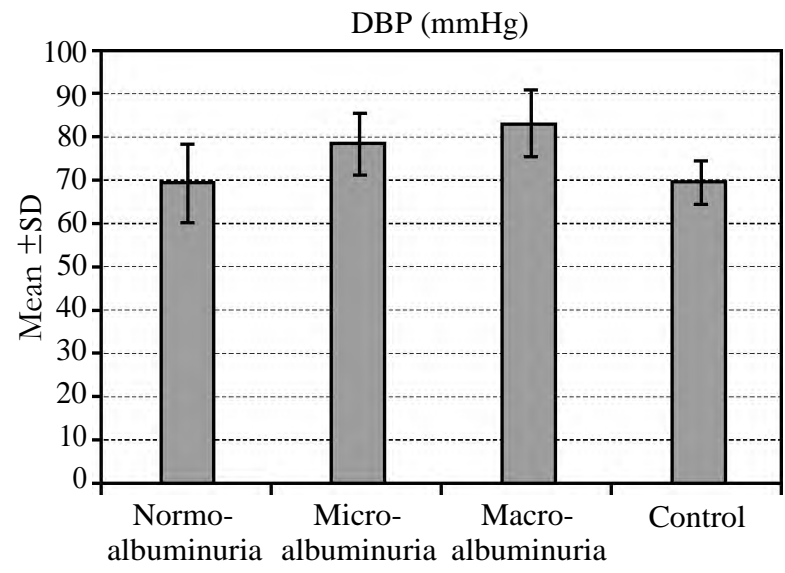

Fig. (2): Comparison between studied groups regarding DBP 
Group III (mean $( \pm$ SD) was $16.167 \pm 2.350$ years) was highly significantly longer regarding the duration of diabetes in comparison to Groups I (mean $( \pm \mathrm{SD})$ was $2.600 \pm 1.276$ years) and II (mean $( \pm \mathrm{SD})$ was $7.667 \pm 1.440$ years).

Fasting Blood Glucose (FBG) was non significantly increased in Group II mean \pm SD (112.000 $\pm 10.875)$ and Group III mean \pm SD (142.933 \pm $13.955)$ when compared with Group IV mean \pm SD

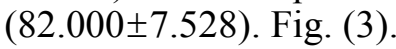

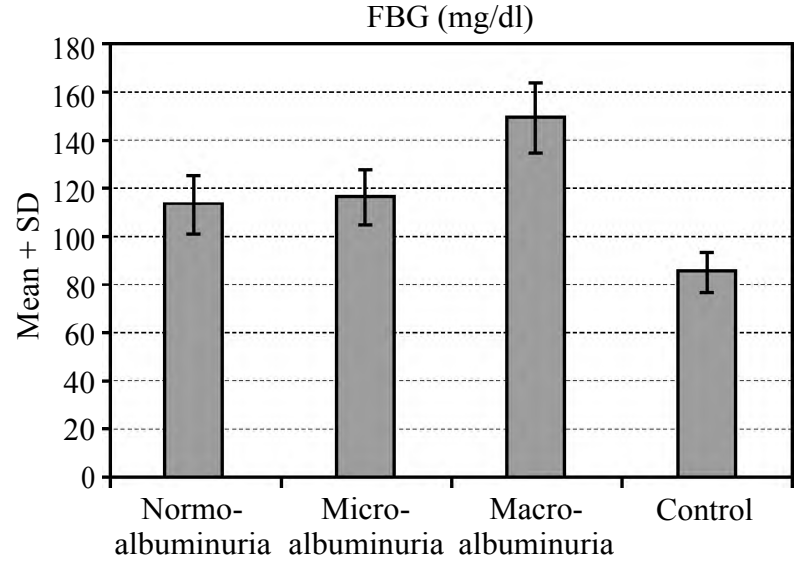

Fig. (3): Comparison between studied groups regarding FBG.

According to Post Prandial Blood Glucose (PPBG), there was highly significant increase in Groups II mean \pm SD $(176.600 \pm 23.231)$ and III mean \pm SD $(186.800 \pm 23.944)$ in relation to Group IV mean \pm SD (118.500 \pm 472$)$. Fig. (4).

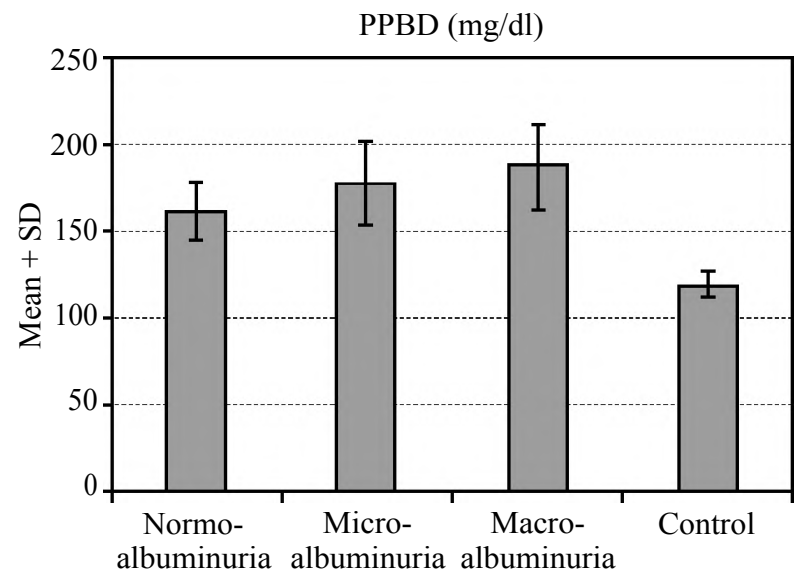

Fig. (4): Comparison between studied groups regarding PPBG.

$\mathrm{HbA}_{1 \mathrm{c}}$ was highly significant increased in Groups I mean \pm SD $(6.787 \pm 0.306)$, II mean \pm SD $(7.113 \pm 0.961)$ and III mean \pm SD $(7.617 \pm 0.704)$ when compared with Group IV mean \pm SD (5.480 $\pm 0.352)$. Fig. (5).

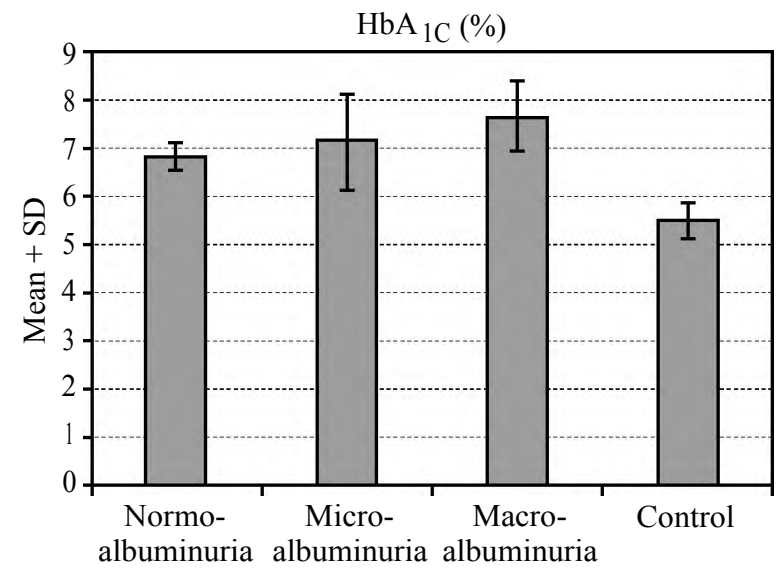

Fig. (5): Comparison between studied groups regarding $\mathrm{HbA}_{1 \mathrm{c}}$

Groups II mean \pm SD $(1.340 \pm 0.426)$ and III mean $\pm \mathrm{SD}(1.961 \pm 0.563)$ revealed highly significant increase of serum creatinine when compared to Group IV mean \pm SD $(0.858 \pm 0.128)$. Fig. (6).



Fig. (6): Comparison between studied groups regarding serum creatinine.

Blood urea was highly significant increased in Group III mean \pm SD $(52.333 \pm 10.720)$ when compared with Groups I, II and IV mean \pm SD $(33.033$ $\pm 6.672,36.867 \pm 3.902$ and $26.100 \pm 5.280)$ respectively. Fig. (7).

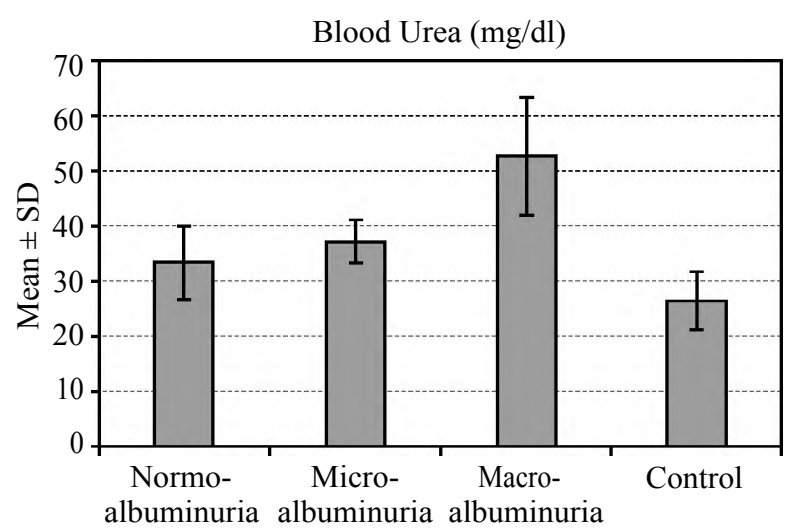

Fig. (7): Comparison between studied groups regarding blood urea. 
There was significant decrease in Estimated Glomerular Filtration Rate (eGFR) in Group I and highly significant decrease in groups II and III compared to Group IV. Also, there was high significantly decrease in Group III compared with Group II. Table (1) \& Fig. (8).

Table (1): Comparison between studied groups regarding estimated Glomerular Filtration Rate (eGFR).

\begin{tabular}{|c|c|c|c|c|c|}
\hline \multirow{2}{*}{\multicolumn{2}{|c|}{ Groups }} & \multicolumn{2}{|c|}{ eGFR (ml/min) } & \multicolumn{2}{|c|}{ ANOVA } \\
\hline & & Range & Mean \pm SD & $\mathrm{F}$ & $p$-value \\
\hline \multirow{4}{*}{\multicolumn{2}{|c|}{$\begin{array}{l}\text { Normoalbuminuria (I) } \\
\text { Microalbuminuria (II) } \\
\text { Macroalbuminuria (III) } \\
\text { Control (IV) }\end{array}$}} & $80-120$ & $99.667 \pm 12.101$ & \multirow[t]{4}{*}{71.852} & \multirow[t]{4}{*}{$<0.001 *$} \\
\hline & & $38-95$ & $67.533 \pm 18.671$ & & \\
\hline & & $30-90$ & $52.467 \pm 16.710$ & & \\
\hline & & $99-125$ & $116.800 \pm 8.753$ & & \\
\hline \multicolumn{6}{|c|}{ TUKEY'S Test } \\
\hline I \& II & I \& III & I \& IV & II \& III & II \& IV & III \& IV \\
\hline$<0.001 *$ & $<0.001 *$ & $0.017^{*}$ & $0.002 *$ & $<0.001 *$ & $<0.001 *$ \\
\hline
\end{tabular}

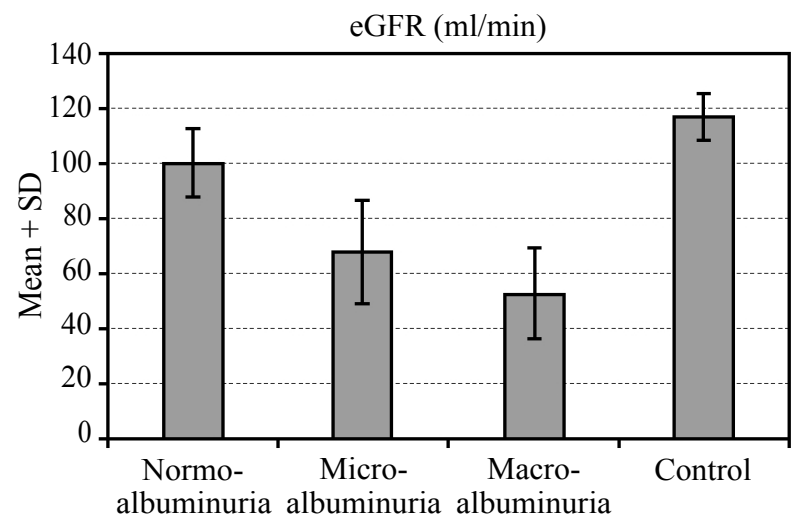

Fig. (8): Comparison between studied groups regarding eGFR.

According to ACR, there was nonsignificant difference between Group I and Group IV. There was nonsignificant difference of ACR in Group II when compared to Group IV while there was highly significant increase when compared with Group I. Group III revealed highly significant increase when compared with Group I, II and IV. Table (2) \& Fig. (9).

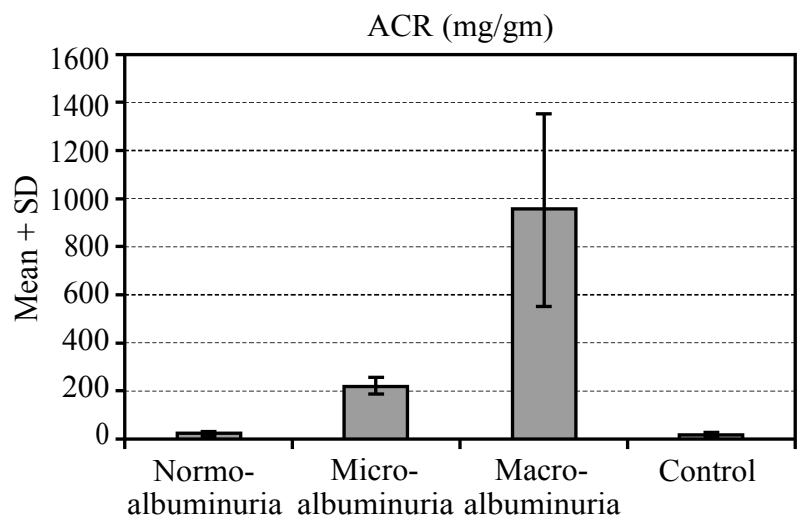

Fig. (9): Comparison between studied groups regarding ACR.
Table (2): Comparison between studied groups regarding ACR.

\begin{tabular}{|c|c|c|c|c|}
\hline \multirow{2}{*}{ Groups } & \multicolumn{2}{|c|}{$\mathrm{ACR}(\mathrm{mg} / \mathrm{gm})$} & \multicolumn{2}{|c|}{ ANOVA } \\
\hline & Range & Mean \pm SD & $\mathrm{F}$ & $p$-value \\
\hline $\begin{array}{l}\text { - Normoalbuminuria } \\
\text { (I) }\end{array}$ & $10-30$ & $18.433 \pm 6.468$ & 110.099 & $<0.001 *$ \\
\hline $\begin{array}{l}\text { - Microalbuminuria } \\
\text { (II) }\end{array}$ & $180-300$ & $217.667 \pm 35.534$ & & \\
\hline $\begin{array}{l}\text { - Macroalbuminuria } \\
\text { (III) }\end{array}$ & $630-2100$ & $943.100 \pm 392.272$ & & \\
\hline - Control (IV) & $10-25$ & $16.700 \pm 5.293$ & & \\
\hline \multicolumn{5}{|c|}{ TUKEY'S Test } \\
\hline I \& III & I \& IV & II \& III & I\& IV & III \& IV \\
\hline$<0.001^{*}$ & 1.000 & $<0.001^{*}$ & 0.060 & $<0.001^{*}$ \\
\hline
\end{tabular}

Urinary podocalyxin was highly significant increased in Group I when compared to Group IV. Urinary podocalyxin was highly significant increased in Group II when comparing Group I and Group IV. Also, there was highly significant increase in urinary podocalyxin in Group III when compared with Group I, II and Group IV. Table (3) \& Fig. (10).

Table (3): Comparison between studied groups regarding urinary podocyte-associated protein (podocalyxin).

\begin{tabular}{|c|c|c|c|c|}
\hline \multirow{2}{*}{ Groups } & \multicolumn{2}{|c|}{ Podocalyxin (ng/ml) } & \multicolumn{2}{|c|}{ ANOVA } \\
\hline & Range & Mean \pm SD & $\mathrm{F}$ & $p$-value \\
\hline $\begin{array}{l}\text { - Normoalbuminuria } \\
\text { (I) }\end{array}$ & $10.9-25.3$ & $18.047 \pm 3.828$ & 194.304 & $<0.001 *$ \\
\hline $\begin{array}{l}\text { - Microalbuminuria } \\
\text { (II) }\end{array}$ & $16.2-32.1$ & $27.307 \pm 3.245$ & & \\
\hline $\begin{array}{l}\text { - Macroalbuminuria } \\
\text { (III) }\end{array}$ & $25.1-53.2$ & $40.347 \pm 7.536$ & & \\
\hline - Control (IV) & $0.514-1.453$ & $0.857 \pm 0.349$ & & \\
\hline
\end{tabular}

\begin{tabular}{lccccc}
\hline \multicolumn{6}{c}{ TUKEY'S Test } \\
\hline I \& II & I \& III & I \& IV & II \& III & II \& IV & III \& IV \\
\hline$<0.001^{*}$ & $<0.001^{*}$ & $<0.001^{*}$ & $<0.001 *$ & $<0.001 *$ & $<0.001^{*}$ \\
\hline
\end{tabular}

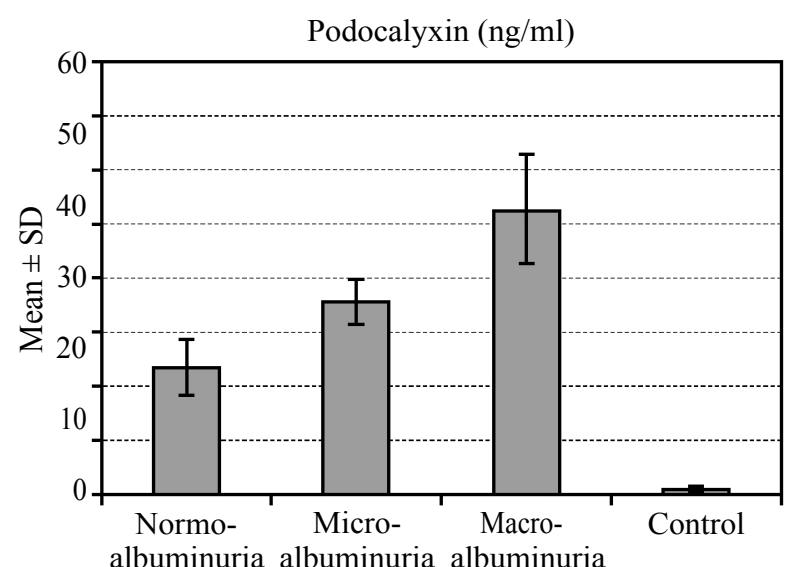

Fig. (10): Comparison between studied groups regarding podocalyxin. 
ACR was correlated positively with DBP, FBG, PPBG, $\mathrm{HbA}_{l_{\mathrm{c}}}$, serum creatinine, blood urea and duration of diabetes. While it correlated negatively with eGFR. There was no correlation between ACR and age, sex and SBP. Table (4) \& Figs. (11A-C).

Urinary podoclyxin correlated positively with SBP, DBP, FBG, PPBG, $\mathrm{HbA}_{1_{\mathrm{c}}}$, serum creatinine, blood urea, ACR and duration of diabetes. While it correlated negatively with eGFR. There was no

Table (4): Correlation between ACR and all variables in all studied groups.

\begin{tabular}{|c|c|c|}
\hline \multicolumn{3}{|c|}{ Correlations } \\
\hline \multirow{2}{*}{ Variables } & \multicolumn{2}{|c|}{$\mathrm{ACR}(\mathrm{mg} / \mathrm{gm})$} \\
\hline & $r$ & $p$-value \\
\hline Age & 0.168 & 0.114 \\
\hline Sex & 0.708 & 0.481 \\
\hline SBP & 0.179 & 0.092 \\
\hline DBP & 0.475 & $<0.001 *$ \\
\hline FBG (mg/dl) & 0.651 & $<0.001 *$ \\
\hline PPBG (mg/dl) & 0.261 & $0.013^{*}$ \\
\hline HbA1c (\%) & 0.427 & $<0.001^{*}$ \\
\hline Serum creatinine $(\mathrm{mg} / \mathrm{dl})$ & 0.488 & $<0.001 *$ \\
\hline Blood Urea (mg/dl) & 0.710 & $<0.001 *$ \\
\hline eGFR (ml/min) & -0.601 & $<0.001^{*}$ \\
\hline Duration of DM & 0.833 & $<0.001 *$ \\
\hline
\end{tabular}


correlation between urinary podocalyxin and age and sex. Table (5) \& Figs. (12A-D).

The ROC curve was used to assess the potential utility of urinary podocalyxin for early detection of diabetic kidney disease in our patients. Cutoff value $>1.45$ differentiated between diabetic patients and control with sensitivity $100 \%$ and specificity of $100 \%$. Table (6) \& Fig. (13).

Table (5): Correlation between urinary podocalyxin and all variables in all studied groups.

\begin{tabular}{lcl}
\hline \multicolumn{3}{c}{ Correlations } \\
\hline Variables & \multicolumn{2}{c}{ Podocalyxin $(\mathrm{ng} / \mathrm{ml})$} \\
\cline { 2 - 3 } & $r$ & $p$-value \\
\hline Age & 0.201 & 0.057 \\
Sex & 0.690 & 0.492 \\
SBP & 0.351 & $0.001^{*}$ \\
DBP & 0.466 & $<0.001^{*}$ \\
FBG (mg/dl) & 0.705 & $<0.001^{*}$ \\
PPBG (mg/dl) & 0.473 & $<0.001^{*}$ \\
HbA1C (\%) & 0.471 & $<0.001^{*}$ \\
Serum creatinine (mg/dl) & 0.538 & $<0.001^{*}$ \\
Blood Urea (mg/dl) & 0.618 & $<0.001^{*}$ \\
eGFR (ml/min) & -0.669 & $<0.001^{*}$ \\
ACR (mg/gm) & 0.730 & $<0.001^{*}$ \\
Duration of DM (yrs) & 0.878 & $<0.001^{*}$ \\
\hline
\end{tabular}

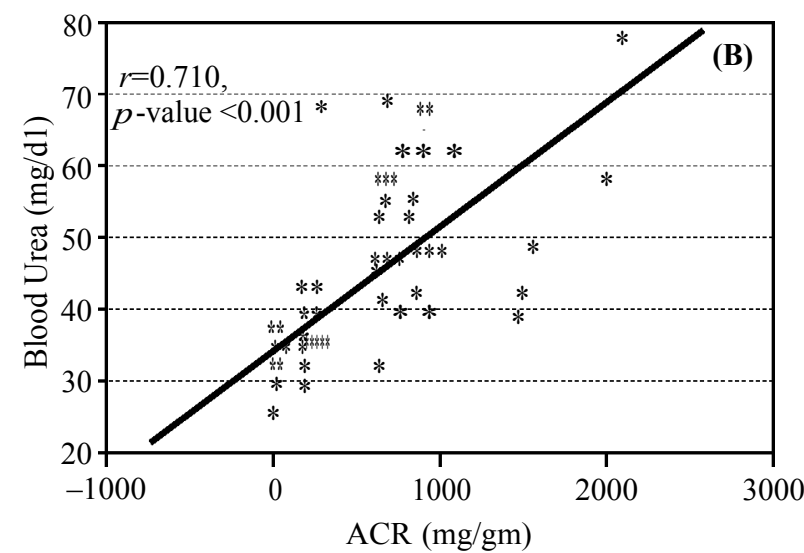

Figs. (11A, B, C): Positive correlation between ACR, serum creatinine and blood urea. While negative correlation between ACR and eGFR. 

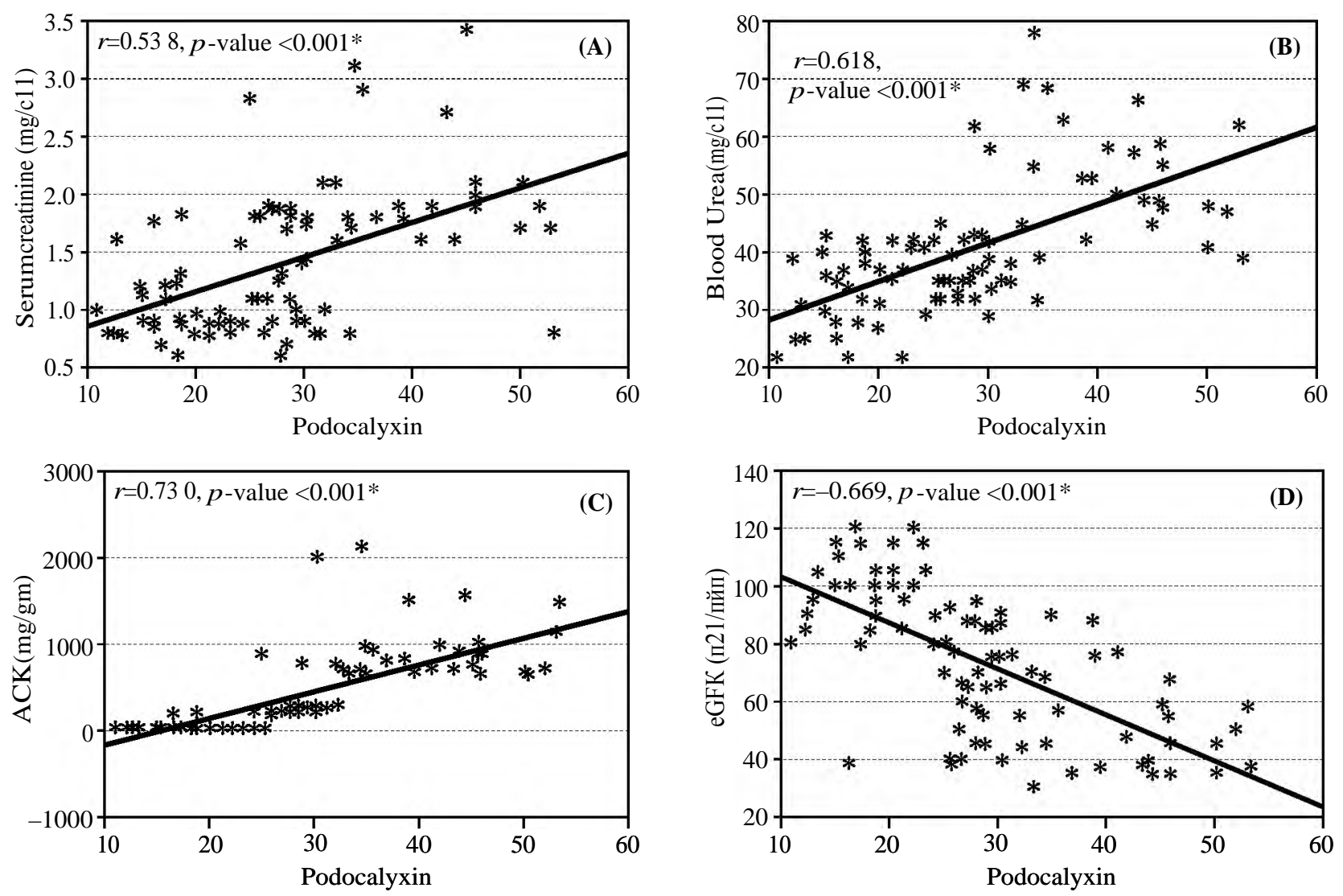

Figs. (12A, B , C): Positive correlation between podocalyxin, serum creatinine, blood urea and ACR. While negative correlation between podocalyxin and eGFR.

Table (6): Show sensitivity, specificity, PPV, NPV and accuracy of urinary Podocalyxin (patients and control groups).

\begin{tabular}{ccccccc}
\hline & \multicolumn{6}{c}{ ROC curve between diabetic patients and control } \\
\cline { 2 - 7 } & Cutoff & Sens. & Spec. & PPV & NPV & Accuracy \\
\hline Podocalyxin & $>1.45$ & 100.00 & 100.00 & 100.00 & 100.00 & $100 \%$ \\
\hline
\end{tabular}

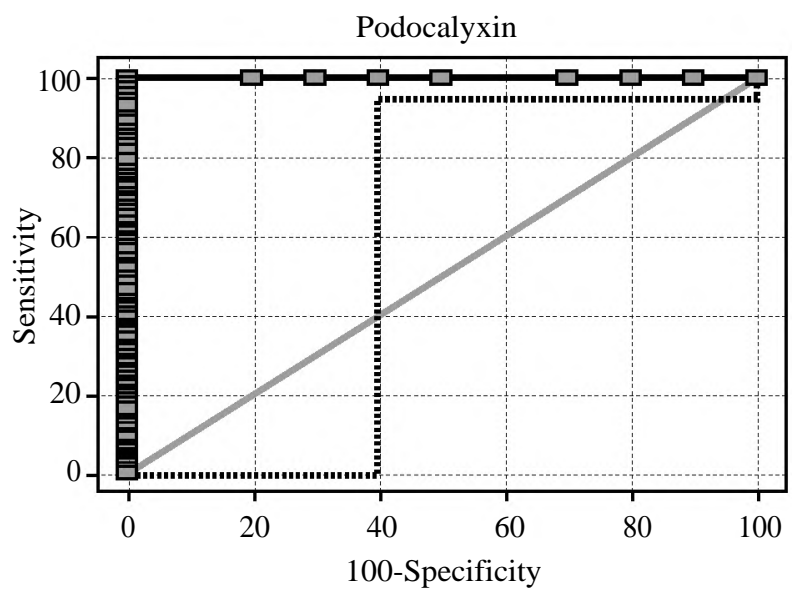

Fig. (13): Show sensitivity, specificity, PPV, NPV and Accuracy of urinary Podocalyxin (patients and control groups).

\section{Discussion}

There was significant elevation of Systolic Blood Pressure (SBP) and Diastolic Blood Pressure (DBP) in microalbuminuria and macroalbuminuria groups relative to the control group. This was coincided with Gall [8] and Ali [9] who found that DBP increased with increased albuminuria being $48 \%, 68 \%$ and $85 \%$ in patients with normoalbuminuria, microalbuminuria and macroalbuminuria respectively. So, they recommended early detection of microalbuminuria and to start treatment without any delay to guard against hypertension and its future complications.

Blood glucose profile including FBG, PPBG and $\mathrm{HbA}_{1 \mathrm{c}}$ was highly significant elevated in macroalbuminuria group compared to normoalbuminuria and microalbuminuria groups. This was in agreement with Kundu et al., 2013 [10] who reported that fasting and post prandial blood glucose, $\mathrm{HbA}_{1 \mathrm{c}}$ were linearly correlated to the level of urinary albumin excretion.

There was highly significant increase of serum creatinine level especially microalbuminuria and 
macroalbuminuria groups. This was supported by Bamanikar et al., 2016 [11] who found elevated Blood Urea Nitrogen (BUN) and serum creatinine in uncontrolled diabetic patients. Also, Sirivole \& Eturi 2017 [13] mentioned that there was a strong relationship between blood sugar levels, development of DKD and elevated renal function parameters as serum creatinine and blood urea.

There was significant decrease in eGFR and significant increase of BUN in diabetic patients especially microalbuminuria and macroalbuminuria groups than that of the healthy control group. These findings were in agreement with a previous study done by Fontela et al., 2014 [13] who reported that GFR decreased in patients with type 2 diabetes mellitus. Also, there is another cohort study was done by Zoppini et al., 2012 [14] on type 2 diabetic patients for 10 years found that the rate of eGFR declined annually without any significant difference between sexes and that the most powerful risk factor of annual eGFR decline was abnormal albuminuria; microalbuminuria and macroalbuminuria, respectively.

There was highly significant increase of Albu$\mathrm{min} /$ Creatinine Ratio (ACR) in macroalbuminuria compared to all groups observed in this study. This was in agreement with Jeon et al., 2013 [15] who reported that ACR was markedly elevated in patients with diabetic nephropathy especially stage III chronic kidney disease and it increased progressively from normoalbuminuria to micro and macroalbuminuria. The elevated ACR among diabetic patients especially those with microalbuminuria and macroalbumiuria might be attributed to impairment of the efficiency of kidney filtration in diabetic patients.

Moreover, this study revealed that ACR was correlated positively with SBP, DBP, FBG, PPBG, $\mathrm{HbA}_{1}$, serum creatinine, blood urea and correlated negatively with eGFR. These findings were in agreement with Robles [16] \& Haque [17] who reported that diabetic patients with macrolbuminuria had an estimated 19 times more rapid decline in renal function than those without albuminuria.

In the present study, urinary podocalyxin was significantly increased in diabetic patients compared to the healthy control group. Also, the level of podocalyxin was significantly increased progressively throughout the normoalbuminuria, microalbuminuria and macrolbuminuria groups. The elevated podocalyxin in normoalbuminuria comparing to healthy controls suggested that podocytes injury occurred before the appearance of micro- albuminuria in diabetic patients. These results were consistent with Liodaki et al., 2015 [18] who found that excretion of podocyte markers in urine increased in normoalbuminuric patients with diabetes. However, there was a conflicted finding with $\mathrm{Na}-$ kamura [19] \& Shoji [20] who demonstrated that urinary podocytes were absent in diabetic patients with normoalbuminuria but detected in microalbuminuric and in macroalbuminuric patients by immunofuorescence as regard the normoalbuminuric group.

Also, Rodrigues et al., 2014 [21] found that urinary mRNA profiles of podocalyxin, a-actin4 and podocin were increased with the progression of DKD which suggested that quantification of podocytes-associated molecules in urine will be a useful biomarker of DKD. Some have suggested that podocytes damage occurs in early diabetes and this might result in defected filtration barrier [22].

The pattern of podocytes injuries in diabetics include cellular hypertrophy, effacement of footprocesses, detachment from the GBM (microvillus transformations \& vesiculation of microvilli which shed into the urine) and apoptosis [23]. High levels of urinary podocalyxin might thus reflect marked microvillus transformation and vesicular shedding [24]. This study showed as Hara et al., 2012 [25] nonsignificant levels of urinary podocalyxin in the healthy controls and that could be explained by a normal physiological turnover as microvillus transformation is found occasionally on the normal glomerulus [26]

In the present study urinary podocalyxin correlated positively with $\mathrm{HbA}_{1_{c}}$, albuminuria and SBP and negatively with eGFR. This was in agreement with Anderson et al., 2015 [27] who reported that podocytes loss contributed to the development of albuminuria. The positive correlation between urinary podocalyxin and $\mathrm{HbAlc}_{\mathrm{c}}$ could point to the role of the uncontrolled diabetes in glomerular capillary barrier damage. Also, the positive correlation between urinary podocalyxin and SBP indicated the important role of blood pressure control in preventing \& treating early DKD. This was in agreement with Zheng et al., 2011 [28] who showed that systolic blood pressure was associated with increased progression of renal disease.

Based on the ROC curve results, urinary podocalyxin might be a useful tool for detection of early diabetic kidney disease with cutoff value $>1.45$ differentiated between diabetic patients and control with sensitivity $100 \%$ and specificity of $100 \%$. 
This was reported in previous researches which mentioned that urinary synaptopodin, podocalyxin, a-actin 4 , and podocin mRNA were significantly increased in DKD patients compared with healthy controls. Also, Wang et al., 2007 [29] demonstrated that specific urinary podocyte markers as nephrin, podocin, synaptopodin, Wilms' tumor-1 and aactin 4 were increased in patients with DKD.

\section{Conclusion:}

Measurement of urinary podocyte-associated protein is a useful, practical and non-invasive tool for the evaluation of renal involvement in the course of diabetes.

The study pet faults:

- Number of patients was a small number.

- Period of follow-up was short.

\section{Recommendations:}

We recommend more studies on a large number of patients for a longer period of follow-up for detection of the usefulness of the use of urinary podocalyxin in detection of diabetic nephropathy in type II diabetes mellitus.

\section{References}

1- American Diabetes Association: Standards of Medical Care in Diabetes. Diabetes Care, 40: 1-129, 2017.

2- American Diabetes Association: Standards of medical care in diabetes. Diabetes Care, 37: 14-80, 2015.

3- HANEDA M., UTSUNOMIYA K., KOYA D., et al.: A new Classification of Diabetic Nephropathy 2014: A report from Joint Committee on Diabetic Nephropathy. J. Diabetes Investig, 6 (2): 242-6, 2015.

4- RIGALLEAU V., LASSEUR C., RAFFAITIN C., et al.: Normoalbuminuric renal insufficient diabetic patients. A lower risk group. Diabetes Care, 30: 2034-9, 2007.

5- GARTNER L.P. and HIATT S.: Cell Biology and Histology. Lippincott Williams and Wilkins, 978 (8): 7817 8577, 2007.

6- HARA M., YANAGIHARA T., KIHARA I., et al.: Apical cell membranes are shed into urine from injured podocytes: A novel phenomenon of Podocyte injury. J. Am. Soc. Nephrol., 16: 408-16, 2005.

7- American Diabetes Association: Classification and Diagnosis of Diabetes. In Standards of Medical Care in Diabetes. Diabetes Care, 39: 13-22, 2016

8- GALL M.A., ROSSING P., SKOTT P., et al.: Prevalence of micro-and macroalbuminuria, arterial hypertension, retinopathy and large vessel disease in European Type 2 (non-insulin-dependent) diabetic patients. Diabetologia, 34: 655-61, 1991.

9- ALI A., TAJ A., AMIN M.J., et al.: Correlation between Microalbuminuria and Hypertension in Type 2 Diabetic Patients. Pak. J. Med. Sci., 30 (3): 511-4, 2014.
10- KUNDU D., ROY A., MANDAL T., et al.: Relation of microalbuminuria to glycosylated hemoglobin and duration of type 2 diabetes. Nigerian Journal of Clinical Practice, 16 (2): 216-20, 2013.

11- BAMANIKAR S.A., BAMANIKAR A.A. and ARORA A.: Study of Serum urea and Creatinine in Diabetic and non-diabetic patients in in a tertiary teaching hospital. The Journal of Medical Research, 2 (1): 12-5, 2016.

12- SIRIVOLE R.M. and ETURI S.: A study on blood urea and serum creatinine in diabetes mellitus from Sangareddy District, Telangana, India. International Journal of Medical and Health Research, 3 (12): 132-6, 2017.

13- FONTELA P.C., WINKELMANN E.R., OTT J.N., et al.: Estimated glomerular filtration rate in patients with type 2 diabetes mellitus. Rev. Assoc. Med. Bras., 60 (6): 5317,2014

14- ZOPPINI G., TARGHER G., CHONCHOL M., et al.: Predictors of Estimated GFR Decline in Patients with Type 2 Diabetes and Preserved Kidney Function. Clinical Journal of the American Society of Nephrology, 7 (3): 401-8, 2012.

15- JEON Y.L., KIM M.H., LEE W.I., et al.: Cystatin C as an early marker of diabetic nephropathy in patients with type 2 diabetes. Clin. Lab., 59 (11-12): 1221-9, 2013.

16- ROBLES N.R., VILLA J. and GALLEGO R.H.: NonProteinuric Diabetic Nephropathy. J. Clin. Med., 4 (9): 1761-73, 2015.

17- HAQUE N., DEBNATH B.C., IBRAHIM M., et al.: Association of $\mathrm{HbA}_{1 \mathrm{c}}$ with Urinary ACR \& eGFR in Type-2 Diabetes Mellitus. Original Article, 5 (1): 6-11, 2011.

18- LIOUDAKI E., STYLIANOU K.G., PETRAKIS I., et al. Increased Urinary Excretion of Podocyte Markers in Normoalbuminuric Patients with Diabetes. Nephron, 131: 34-42, 2015.

19- NAKAMURA T., USHIYAMA C., SUZUKI S., et al.: Urinary podocytes for the assessment of disease activity in lupus nephritis. Am. J. Med. Sci., 31: 673-89, 2000.

20- SHOJI M., KOBAYASHI K., TAKEMOTO M., et al.: Urinary podocalyxin levels were associated with urinary albumin levels among patients with diabetes. Journal Biomarkers, 21 (2): 164-7, 2015.

21- RODRIGUES P.G., BRINGHENTI R.N., NASCIMENTO J.F., et al.: Expression patterns of podocyte-associated mRNAs inpatients with proliferative or non-proliferative glomerulopathies. Int. J. Clin. Exp. Pathol., 7 (5): 2185 98, 2014.

22- THARAUX P.L. and HUBER T.B.: How Many Ways Can a Podocyte Die? Seminars in Nephrology, 32 (4): 394404, 2012.

23- MOHAMED A.H., HEIBAH H.A., IBRAHIM H.E., et al.: Urinary Podocalyxin; a potential new marker for early diabetic nephropathy in type 2 diabetes mellitus. Indian Journal of Applied Research, 6 (1): 2249-555, 2016.

24- HARA M., YANAGIHARA T., HIRAYAMA Y., et al.: Podocyte membrane vesicles in urine originate from tip vesiculation of podocyte microvilli. Hum. Pathol., 41: $1265-75,2010$ 
25- HARA M., YAMAGATA K., TOMINO Y., et al.: Urinary podocalyxin is an early marker for podocyte injury in patients with diabetes: establishment of a highly sensitive ELISA to detect urinary podocalyxin. Diabetologia, 52: 2913-9, 2012

26- AGAWA A., YASUDA M., KUME S., et al.: Impaired Podocyte Autophagy Exacerbates Proteinuria in Diabetic Nephropathy. Diabetes, 65 (3): 755-67, 2016.

27- ANDERSON A.H., YANG W., TOWNSEND R.R., et al.: Time-updated systolic blood pressure and the progression of chronic kidney disease: Findings from the Chronic Renal Insufficiency Cohort (CRIC) Study. Ann. Intern. Med., 162 (4): 258-65, 2015.

28- ZHENG M., LV L.L., NI J., et al.: Urinary podocyteassociated mRNA profile in various stages of diabetic nephropathy. PLOS One, 6 (5): 204-31, 2011.

29- WANG G., LAI F.M., LAI K.B., et al.: Messenger RNA expression of podocyte-associated molecules in the urinary sediment of patients with diabetic nephropathy. Nephron. Clin. Pract, 106: 169-79, 2007.

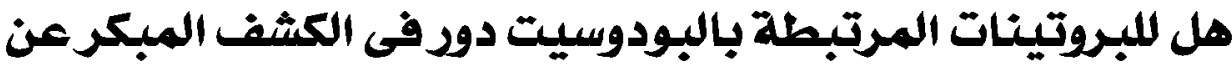

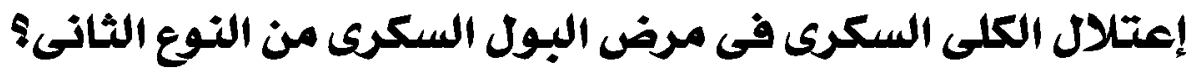

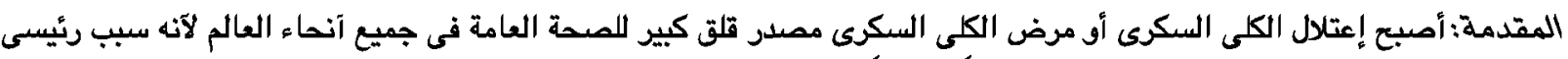



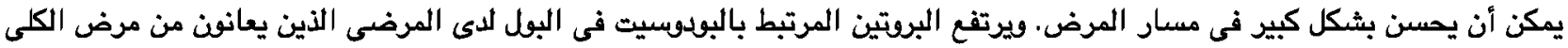

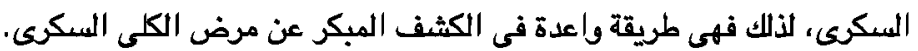

الهدف من البحث: دراسة دود البروتين المرتبط بالبودوسيت فى الكشف المبكر عن إعتلال الكلى السكرى فى مرضى البول السكرى من

المرضى وطرق البحث: آجريت دراسة عرضية على تسعين من مرضى البول السكرى من النوع الثئ الثانى. تم تقسيمهم بالتساوى إلى ثلاث



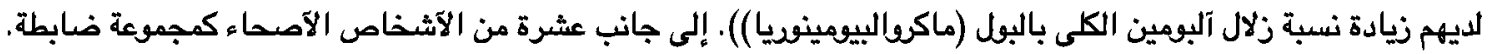

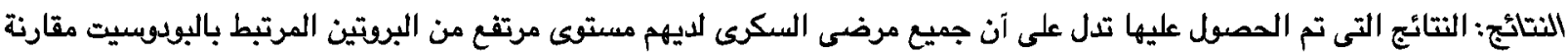



الإستتاج: أظهرت هذه الدراسة آن قياس البروتين المرتبط بالبواوسيت فى البول هو مؤشر حيوى محتمل للكشف المبكر عن مرضى الكلى
} 